\title{
The shape of things to come: How marketing services organisations anticipate the future
}

\author{
RECEIVED (IN REVISED FORM): 30 NOVEMBER, 2000
}

Roger Bennett and Rita Kottasz

Department of Business Studies, London Guildhall University, 84 Moorgate, London EC2M 6SQ

Tel: (+44) 0207320 1577; Fax: (+44) 0207320 1465; e-mail: rbennett@lgu.ac.uk or rkottasz@lgu.ac.uk.

\section{Dr. Roger \\ Bennett and Ms \\ Rita Kottasz are \\ respectively \\ Reader and \\ Lecturer in the \\ Centre for \\ Research in \\ Corporate and \\ Marketing \\ Communications, \\ Department of \\ Business Studies, \\ London Guildhall \\ University.}

\begin{abstract}
Respondents in 70 advertising agencies, 70 public relations firms and 67 marketing research companies completed a mail questionnaire regarding their business's anticipatory analysis (future gazing) activities. It emerged that the extent to which a firm was likely to engage in anticipatory analysis depended substantially on its innate innovativeness, the scope of its conventional planning and forecasting systems, and the degree to which its management believed that future client requirements would differ radically from the prevailing ones. Environmental complexity, volatility and competitive intensity seemed to encourage firms to adopt somewhat casual and intuitive approaches to future gazing. Advertising agencies undertook anticipatory analysis to a greater degree than marketing research companies. This latter outcome is compatible with the views expressed by a number of previous writers who have argued that conventional marketing research is predicated on the past and inhibits the meaningful contemplation of future scenarios and possibilities.
\end{abstract}

\section{INTRODUCTION}

Providers of marketing consultancy services thrive on change. They supply knowledge and expertise in areas where client businesses lack experience and where familiarity with the latest marketing methods and thinking is vital for gaining competitive advantage. Often the success of an advertising agency, marketing research firm or public relations company depends on its ability to stay 'ahead of the game' and hence to be among the first to offer expertise in recently introduced marketing methods. Obvious examples of new client demands arising over the last couple of decades include the implementation of integrated marketing communications, reputation management (as distinct from the management of corporate image and identity), cause related marketing and, of course, a plethora of completely new marketing activities associated with the Internet.

It follows that the systematic contemplation of future client needs 
and business environments should in principle be a critical function within a marketing company. Among other things, this could help an organisation to determine a clear strategic direction $^{1}$ recognise warning signals and avoid surprises ${ }^{2}$ and generally shape current decisions that might impact on future operations. ${ }^{3}$ Further advantages of remaining ahead of the game, according to Simkin, include 'serving the "best" customers, minimising threats, maximising returns and using resources to the greatest advantage'. ${ }^{4}$ Management is forced to evaluate the relevance of its current assumptions about future developments ${ }^{5}$ and to examine the feasibilities of alternative courses of action. $^{6}$

Yet, despite the patent importance of the subject, hardly anything is known about the methods that marketing services firms actually use for gazing into the future. The aim of the present paper is to contribute to knowledge in the area by presenting the results of a survey of the futuregazing practices of a sample of 207 marketing services providers (70 advertising agencies, 70 public relations consultancies and 67 market research firms) and of respondents' perceptions of the main factors influencing decisions to invest heavily in future-gazing activities. A number of hypotheses derived from the literature on orthodox corporate planning and forecasting are tested. The relationship between future gazing and performance is examined and discussed.

\section{FUTURE GAZING VERSUS FORECASTING}

'Futurology; the description of what might happen in the future, is not the same as conventional forecasting, which concerns the prediction of future events from past data. ${ }^{7}$ Rather, future gazing attempts to 'paint pictures of what may and could be" and thus involves looking for clues and signs as opposed to collecting data. One of the main purposes of future gazing is to question the firm's fundamental assumptions about potential eventualities. ${ }^{9}$ Hence, instead of considering what has worked in the past, future gazing seeks 'to anticipate creative solutions to problems which have not yet emerged ${ }^{10}$ and to identify a broad range of alternative possibilities. ${ }^{11}$

The practice is sometimes referred to as 'anticipatory analysis'. ${ }^{12-14}$ Satisfactory anticipatory analysis allegedly requires the assumption of a mindset of enquiry, challenge, curiosity and imagination; qualities which, according to GBN Ltd, ${ }^{15}$ induce 'better thinking and an ongoing strategic conversation about the future'. This is quite different from the extrapolation of past or current trends. Gordon, ${ }^{16}$ Christensen ${ }^{17}$ and others have noted how extrapolation based on traditional marketing research methodologies is not capable of describing potential futures since, by definition, it is predicated on the past. Orthodox marketing research, they argued, may be valuable for influencing the present, but does not delineate pathways to 
take the organisation from its present position to situations not previously experienced. ${ }^{18,19}$ Problems with anticipatory analysis include the managerial time it absorbs, its complexity $^{20}$ and its innate subjectivity. ${ }^{21}$ Also, an administrative infrastructure may be needed to execute the activity $^{22}$ and decisions have to be taken regarding which particular managers should be involved in conversations about a firm's possible futures. ${ }^{23}$

\section{PRACTICAL METHODS FOR DESCRIBING THE FUTURE}

Various techniques can be used to describe alternative futures. ${ }^{24-26}$ Scenario building in particular has been advocated as an effective future gazing method. ${ }^{27-31}$ Advantages supposedly accruing to scenario building include the identification (hopefully) of the driving forces influencing change and the constraints on situations, ${ }^{32}$ the evaluation of uncertainties, and the improvement of a company's capacity both to react quickly to unfavourable environments and to cause desirable futures to occur in reality. ${ }^{33}$

Notwithstanding these alleged benefits, several empirical studies have found that, in practice, scenario building is the technique least used by companies when looking into the future. ${ }^{34}$ Content analysis is seemingly quite popular (ie the monitoring of the news media to determine, track and evaluate important trends and issues), as is the employment of external advisors. Commonest of all, however, according to Fulmer et al., is the conduct of customer surveys. ${ }^{35}$ Unfortunately, customer surveys might be neither an adequate nor a reliable means for thinking about possible future developments. Gordon noted how the respondents in a customer survey report their past and current feelings and behaviour. ${ }^{36}$ Also, the collateral research accompanying a survey is itself inevitably historical in nature. What firms really needed, Gordon concluded, were systems for 'imagining and creating a series of realities about what might and could be'. ${ }^{37}$ This required a certain attitude of mind; not survey research data. The latter could furnish information needed for insight which in turn might form a basis for the imagination required to move an organisation towards new activities, but this would only happen if the information itself was relevant to the future.

\section{THE INVESTIGATION}

A priori it is to be expected that firms in the marketing services industry should want to describe possible future client needs and situations, as the marketing services industry regularly experiences radical change. ${ }^{38}$ To succeed in fast-changing commercial environments a supplier of marketing services, arguably, must search proactively for the next 'big idea' likely to drive client requirements. Yet, the big idea of tomorrow might not be 
found simply by looking at the big ideas of today. ${ }^{39}$

Jones noted how advertising agencies and PR consultants were sometimes employed to help clients assess the future, although it was unclear as to how extensively they engaged in future gazing in respect of their own operations. ${ }^{40}$ According to Jones the most common anticipatory analysis task undertaken on behalf of clients was 'tracking trends as early as possible to give clients the chance to develop a competitive edge', ${ }^{41}$ and the assessment of potential demand for completely new products and of possibilities that new types of competition or consumer might emerge. Consequent to their experience of information gathering and interpretation and their familiarity with technical forecasting techniques, marketing research companies might also be presumed to want to engage in anticipatory analysis. Gordon argued, however, that the reality of conventional marketing research practices caused marketing research firms not to be particularly good at future gazing. This was due, she suggested, to three factors. First, narrow mindedness arising from the evolution of marketing research from being a multidisciplinary subject to its fragmentation into a series of specialisms. Secondly, lack of communication between quantitative and qualitative researchers and subject specific groups within marketing research companies. Thirdly, an 'obsession with research techniques and methodologies at the expense of foresight and imagination'. ${ }^{42}$ Christensen similarly noted a number of reasons for supposing that traditional marketing research may be less valuable for contemplating radical changes in future circumstances than for sustaining existing activities. ${ }^{43}$ This was unfortunate, Christensen continued, because the rapid pace of environmental change increasingly altered the basic dimensions of business problems and activities so that a fundamental rethink about all aspects of a firm's operations was sometimes required. Clearly, it is a matter of considerable interest to enquire whether market research firms in reality neglect the anticipatory analysis function to the degree that Christensen, Gordon and others ${ }^{44}$ have suggested.

\section{Hypotheses}

Several hypotheses previously tested by researchers investigating the factors that might encourage investment in standard marketing planning and forecasting systems could have parallels in the anticipatory analysis field. For instance, intense competition has been found to induce firms to undertake extensive planning and forecasting. ${ }^{45,46}$ It is pertinent to ask whether the same holds true vis-à-vis future-gazing activities. Accordingly, it is hypothesised that:

H1: Marketing services firms which operate in highly competitive markets engage in anticipatory 
analysis to a significantly greater extent than businesses in less competitive markets.

Competitive intensity can contribute to 'environmental volatility'. The latter has been defined as 'a combination of radical and frequent change with a significant level of perceived uncertainty'. ${ }^{47}$ Cooper suggested that, in the face of intense environmental volatility, "the most valuable strategic assets that managers possess for enabling them to innovate in rapidly changing times are the mental models and tools people use to think about the future' ${ }^{48}$ Possibly, firms in highly volatile environments have greater incentives to look into the future. Volatility makes it more difficult to form a view of the future consequent to greater uncertainty about markets, competitors and customers. Hence, the existence of a volatile environment might stimulate businesses to devote more time and effort to mapping out various possible futures. On the other hand, volatility may encourage a casual and highly informed approach to the issue on the assumption that severe volatility makes it impossible to identify alternative scenarios. Hence, there is little point in devoting resources to future gazing exercises. ${ }^{49}$ In the latter case the firm may be expected to proceed intuitively, to base assessments on managerial hunches and experience, and to act in a manner 'not unlike the way one might try to find the way out of an unfamiliar room in the dark' ${ }^{50}$ For operational purposes it is hypothesised that:

$\mathrm{H} 2$ : The greater the degree of volatility in the environment in which a firm functions the more it will engage in anticipatory analysis.

Somewhat analogously, a number of researchers have advocated the use of formal planning and forecasting systems as the best means of coping with 'complex' business environments. Others have suggested conversely that highly informal approaches should be applied to situations that are highly complex. ${ }^{51}$ Environmental complexity is connected not only with volatility but also with (i) uncertainties that are difficult to identify and assess and which change very frequently, ${ }^{52}$ (ii) unknown environmental constraints, (iii) occasional chaos, and (iv) a moving kaleidoscope of possibilities. ${ }^{53}$ Hence:

H3: The more complex the environment in which a firm operates the more it will engage in anticipatory analysis.

Whipp et al., ${ }^{54}$ Boynton and Victor ${ }^{55}$ and many other researchers have concluded that strategic flexibility is essential in order to deal effectively with environmental change. ${ }^{56,57}$ This allegedly was because flexibility yielded 'prompt access to finance, expertise, knowledge, co-ordinating systems and internal innovation ${ }^{58}$ Regular and 
careful contemplation of the future might reveal possibilities that encourage a firm to be relatively flexible and hence able to grasp fresh opportunities. This implies:

H4: Firms which engage in substantial anticipatory analysis are more likely to exhibit strategic flexibility than firms which do not engage in substantial anticipatory analysis.

The conclusions drawn from future gazing are inevitably normative and subjective. ${ }^{59,60}$ and the perceptions of the same business environment held by different executives can differ to an enormous degree. Thus, according to Metcalfe $^{61}$ and Mercer ${ }^{62}$ it is hardly surprising that a substantial literature suggests that it is unwise to rely on the thoughts of just one person when contemplating possible futures. Mercer in particular argued that the best way to examine future environments was to form a team consisting of employees of widely disparate occupational status. This encouraged the flexible mindsets needed to foresee future skill and competency requirements ${ }^{63}$ while capturing the wide range of viewpoints essential for creative brainstorming. Thus:

H5: Firms which employ teams to undertake anticipatory analysis are better equipped to cope with the future than firms which rely on just one person to complete this function.
H5(a): Firms which employ multidisciplinary teams for anticipatory analysis are better equipped to cope with the future and,

H5(b): Firms which employ teams comprising employees of different occupational status for anticipatory analysis are better equipped to cope with the future.

Innovative firms are perhaps more likely than others to welcome change and to undertake activities that will help them shape their futures. ${ }^{64,65}$ Such enterprises will strive to be among the first to introduce new methods and will want to stay ahead of their rivals. In principle, this should create the desire to explore future possibilities, implying:

H6: The more innovative a business, the greater the extent to which it will engage in anticipatory analysis.

\section{The questionnaire}

In order to explore these matters a questionnaire was drafted consequent to a literature review in the fields of futurology, ${ }^{66-70}$ business forecasting, ${ }^{71-74}$ planning, ${ }^{75-78}$ market research, ${ }^{79-83}$ and organisational change behaviour. ${ }^{84-87}$ This was pretested via discussions with four senior executives in advertising, PR and market research firms and a preliminary mailing to 50 companies selected at random from the sampling frame used for the main study (see below). Twelve replies were 
received from the initial mailout which, together with the outcomes to the interviews with the four industry contacts, facilitated the rewording of ambiguous questions and the removal of merging of excessively overlapping items. The final version of the questionnaire was distributed to 600 businesses (200 in each of the three sectors considered) randomly chosen (using the random number generator available on SPSS) from the year 2000 editions of the 'Advertiser's Annual' (Hollis Directories Ltd) and the 'International Directory of Market Research Organisations' (Market Research Society).

Section 1 of the questionnaire examined the extent of, and attitudes towards, future gazing within a company. This was followed by a section concerning future gazing methods, another about the firm's environmental circumstances and organisational characteristics, and a final set of items exploring the respondent's confidence in the future and his or her assessments of various performance satisfaction measures. The questionnaire was mailed to the 'Head of New Business Development' in each firm. After a follow up, 70 replies were received from advertising agencies (35 per cent of the sampling frame), 70 from public relations consultancies (35 per cent), and 67 from market research companies (33 per cent). Twenty firms reported they were advertising agencies which also did public relations and marketing research. These businesses were placed in the adver- tising agency category. (Advertising agencies sometimes possess their own marketing research facilities, though it may be rare for marketing research companies to have an in-house advertising agency — no data on this matter are readily available.) Allowing for returned mail which had been posted to the wrong address and letters from firms indicating they were no longer involved in advertising, PR or marketing research activities, the final effective response rate was 38 per cent. This is quite high for surveys of this type, ${ }^{88}$ indicating perhaps that the recipients found the subject interesting and highly relevant to their businesses. Correspondence and telephone calls received from some of the respondents supported this proposition. Means and standard deviations for the earliest 50 per cent and latest 50 per cent of the returned questionnaires were compared using the Mann-Whitney U-test available on SPSS10, no meaningful differences emerging.

\section{RESULTS}

The 70 advertising agencies in the sample had an average of 83 employees (range 6 to 370); the 70 PR firms had 16 employees on average (range 3 to 151), while the 67 marketing research companies had an average of 77 employees (range 9 to 1,200 ). Table 1 shows the extent to which anticipatory analysis occurred and the methods used in each of the sectors. It can be seen from Table 1(a) that majorities of respondents in all three sectors 
Table 1

\section{EXTENT AND NATURE OF FUTURE GAZING ACTIVITIES (MEAN VALUES $\left.{ }^{\star}\right)$}

(a) This firm possesses formal systems and procedures for thinking about possible future environments.

(b) In this firm a large amount of time and effort is devoted to thinking about future business environments and client needs.

(c) We spend as much time thinking about the characteristics of the client of the future as we spend analysing the client of today.

(d) This firm spends a lot of money on future-gazing activities.

(e) Management gives priority to providing the resources necessary for analysing possible future environments.

(f) We devote much time and effort to searching for information that is relevant to the future.

(g) Our future-gazing activities are extensive.

(h) We monitor the news media and/or the trade press to pinpoint, track and evaluate important issues and trends.

(i) We periodically survey our clients about their possible future activities and needs.

(j) We examine competitors' activities to assess future client needs.

(k) We base our appraisals of the future mainly on 'gut feelings' and intuition.

(l) We believe that painting several alternative scenarios of the future is just as important as forecasting the future by extrapolating the past.

(m) Scenario building and analysis is an important part of our future gazing-activities.

(n) We use external advisers/consultants to help assess possible future scenarios.

(o) Within this firm, teams rather than individuals are responsible for future-gazing activities.

(p) Our processes for thinking about the future involve teams that include lower grade employees as well as senior managers.

(q) Our processes for thinking about the future involve teams that include people from a wide range of business functions and disciplines.
Marketing

Advertising PR research agencies firms firms

$\begin{array}{lll}3.64 & 3.00 \quad 3.62\end{array}$

(0.93) (1.27) (1.32)

$\begin{array}{lll}2.93 & 1.88 & 1.82\end{array}$

$(1.00) \quad(0.93) \quad(1.03)$

$\begin{array}{lll}3.57 & 2.59 & 2.27\end{array}$

(1.16) (1.28) (1.03)

$\begin{array}{lll}3.50 & 2.26 & 2.29\end{array}$

$\begin{array}{lll}(1.11) & (0.67) \quad(1.00)\end{array}$

$\begin{array}{lll}2.96 & 2.41 & 2.38\end{array}$

$\begin{array}{lll}(1.00) & (0.75) \quad(1.02)\end{array}$

$2.88 \quad 2.20 \quad 2.37$

$\begin{array}{lll}(0.91) & (0.88) \quad(1.12)\end{array}$

$2.94 \quad 2.51 \quad 2.31$

$\begin{array}{lll}(1.12) & (0.90) \quad(0.86)\end{array}$

$2.14 \quad 1.90 \quad 2.58$

(0.86) (0.56) (1.12)

$\begin{array}{lll}1.64 & 1.71 \quad 2.53\end{array}$

$\begin{array}{lll}(0.50) & (0.66) \quad(1.09)\end{array}$

$\begin{array}{lll}2.21 & 2.4 & 2.24\end{array}$

(1.05) (0.8) (1.24)

$\begin{array}{lll}2.50 & 3.19 & 3.62\end{array}$

(0.95) (1.17) (1.08)

$\begin{array}{lll}2.63 & 2.24 & 2.81\end{array}$

(1.20) (0.90) (1.50)

$\begin{array}{lll}2.77 & 2.30 & 2.69\end{array}$

(0.99) (1.21) (1.17)

$3.44 \quad 3.71 \quad 4.33$

$\begin{array}{lll}(0.85) & (1.10) \quad(0.97)\end{array}$

$2.93 \quad 2.55 \quad 3.20$

$\begin{array}{lll}(0.92) \quad(1.00) \quad(1.29) & 0\end{array}$

$\begin{array}{lll}3.00 & 2.18 & 3.00\end{array}$

(1.04) (0.95) (0.97)

$\begin{array}{lll}2.81 & 1.90 & 2.90\end{array}$

$(1.00) \quad(0.68) \quad(1.06)$

* Standard deviations in parentheses

Five-point scales: $5=$ strongly agree; $1=$ strongly disagree. 
reported that their firms had 'formal' systems for thinking about the future. Advertising agencies, however engaged in future gazing (items (b) to (g)) to a substantially greater extent than either PR firms or marketing research companies. Note that the PR businesses in the sample were mainly very small enterprises (see above) with limited resources, and this might explain the outcome for the PR subsample. Three questionnaire items asked (5-point scales) whether the respondent's firm possessed the resources (financial, skills, people) to analyse possible future environments. PR firms scored significantly lower ( $p$ $<.05)$ than the other two categories for all three items. Firm size does not, however, explain why the market research companies' responses to Table 1 items (b) to (g) were significantly lower than for the advertising agencies $(\mathrm{p}<.05$ or less in all cases $)$ as the average firm size in both subsamples was nearly identical.

Teamworking was common when firms considered future environments (items (o) and (p)), and external consultants were extensively employed (item (n)). Contrary to the findings reported by Fulmer et al., ${ }^{89}$ the results of this study suggest that scenario building is a popular device for anticipatory analysis, at both the formal (item (m)) and informal (item (l)) levels. Monitoring the news media and trade press ranked second, observing competitors third, and customer surveys fourth (the opposite order to that listed by Fulmer et al.). Note the relatively high propensity of the marketing research firms to rely on 'gut feelings and intuition' (item (k)) in comparison with advertising agencies $(\mathrm{p}<.01)$.

The questionnaire items used to form some of the constructs needed to test the hypotheses (eg organisational flexibility, innovativeness, environmental volatility and complexity) are reproduced in the appendix to the paper. Specific items appearing under the headings 'Organisational flexibility' and 'Innovativeness' were allocated to these categories following a varimax factor analysis which generated a two-factor solution accounting for 71 per cent of total variation within the data. The same procedure was employed to establish which items belonged to each of the 'External environment' constructs (competitive intensity, volatility or complexity). In both analyses, orthogonal rather than oblique rotations were used to separate the items because in neither case did any correlation between pairs of factors exceed 0.34. The appendix gives the Cronbach alphas for the flexibility, innovativeness and environmental volatility and complexity groupings of items, the results indicating reasonable reliability. Hence the items in each construct were composited to form standalone variables. The items for competitive intensity and for the three satisfaction measures were highly intercorrelated within each group and thus were also consolidated into single measures.

Two further potential explanatory variables were created in order to 
complete the analysis. A measure of the extent of a firm's conventional planning and forecasting systems was generated from two items questioning this issue in each case (planning and forecasting) plus an item on the degree of the company's resource investment in orthodox planning and forecasting $(\mathrm{R}=0.69)$. Finally, a variable entitled 'Belief in future change' was formed from the combination $(\mathrm{R}=0.62)$ of two items which asked whether the respondent believed it inevitable that (i) future client requirements would be radically different to client needs of today, and (ii) the firm's future business environment would differ radically from that currently prevailing.

\section{Tests of the hypotheses}

Hypotheses 1, 2, 3 and 6 were tested via the univariate analysis of covariance (ANCOVA) facility available on SPSS10. This involved a regression to explain the overall extent of a firm's future-gazing activities, defined as the composite of items (a) to (g) of Table 1, using firm type (advertising agency, PR or market research company) as the fixed factor (grouping variable). Constructs specifically relevant to the hypotheses and other candidate independent variables that emerged from an analysis of the correlation matrix of questionnaire responses were employed as covariates. The results of the ANCOVA are shown in Table 2, from which it can be seen that hypotheses 2 and 3 are not supported. Competitive intensity ex- erted a marginally insignificant effect at the 0.05 level $(p=0.052)$, so the evidence concerning hypothesis 1 is not convincing. The correlation matrix of the all-sample responses to all the individual questionnaire items was examined to see whether particular items in the environmental volatility and complexity composites correlated substantially with specific items in the dependent variable. This failed to reveal any significant relationships among relevant pairs of items.

Such outcomes are compatible with the view ${ }^{90-94}$ that having to operate within turbulent, keenly competitive, uncertain and complicated markets induces firms not to bother with anticipatory analysis. Further support for this proposition derives from the significance of the correlations observed between environmental volatility and complexity on the one hand and, on the other, a questionnaire item worded:

'We do not believe that it is worth devoting resources to looking into the future because it is simply impossible to describe what the future holds.'

The correlation between this item and environmental volatility was 0.548 , and with environmental complexity 0.394. Moreover, the correlations of volatility and complexity with Table 1 item $(\mathrm{k})$ concerning reliance on 'gut feelings and intuition' were, at 0.35 and 0.37 , positive and significant $(\mathrm{p}<.05)$. 
Table 2

ANALYSIS OF COVARIANCE (DEPENDENT VARIABLE: EXTENT OF A FIRM'S FUTURE GAZING ACTIVITIES)

\begin{tabular}{|c|c|c|}
\hline & & $\begin{array}{l}\text { Beta coefficient } \\
\text { (t-values in } \\
\text { parentheses) }\end{array}$ \\
\hline \multicolumn{2}{|l|}{ Competitive intensity } & $\begin{array}{c}0.125 \\
(1.957)\end{array}$ \\
\hline \multicolumn{2}{|l|}{ Environmental volatility } & $\begin{array}{l}0.04 \\
(0.895)\end{array}$ \\
\hline \multicolumn{2}{|l|}{ Environmental complexity } & $\begin{array}{c}0.021 \\
(0.585)\end{array}$ \\
\hline \multicolumn{2}{|l|}{ Innovativeness } & $\begin{array}{c}0.512 \\
(6.223)^{\star}\end{array}$ \\
\hline \multicolumn{2}{|c|}{ Extent of a firm's conventional planning and forecasting systems } & $\begin{array}{c}0.394 \\
(3.111)^{\star}\end{array}$ \\
\hline \multicolumn{2}{|l|}{ Belief in future change } & $\begin{array}{c}0.139 \\
(1.989)^{\star}\end{array}$ \\
\hline Firm type: Advertising agency & $=3$ & $\begin{array}{c}0.427 \\
(4.803)^{\star}\end{array}$ \\
\hline PR firm & $=2$ & $\begin{array}{l}0.234 \\
(3.604)^{\star}\end{array}$ \\
\hline Marketing research & $=1$ & $\begin{array}{c}0.513 \\
(5.536)^{\star}\end{array}$ \\
\hline
\end{tabular}

Levine error variance statistic $(2,204 \mathrm{df})=.0.532(\mathrm{p}=0.587)$

^Denotes significance at the 0.05 level or less

Inspection of the all-item correlation matrix revealed powerful connections between the items in the Table 2 dependent variable and those in (i) the 'belief in future change' composite, and (ii) the composite reflecting the extent of a firm's conventional planning and forecasting systems. As Table 2 illustrates, the incorporation of the latter composites into the ANCOVA greatly improved its explanatory power. Firm type exerted a highly significant main effect on the dependent variable $(\mathrm{F}[3,198 \mathrm{df}]=$. 11.198). Advertising agencies had the highest mean value for the 
dependent variable, and marketing research companies the lowest. Firm size was initially entered as an independent variable, but was subsequently withdrawn as it failed to attain significance $[p=0.447]$. The fourth hypothesis was assessed via an examination of the correlations between the extent of a firm's future-gazing activities and its degree of strategic flexibility (see the appendix). All the pairwise item correlations were insignificant at the 0.1 level, and the correlation of the two composites was (at $\mathrm{R}=0.19$ ) also insignificant. Thus, $\mathrm{H} 4$ is rejected.

Results pertaining to $\mathrm{H} 5, \mathrm{H} 5$ (a) and H5(b) were mixed. Teamwork (see Table 1 (o)) correlated significantly $(\mathrm{R}=0.44)$ with the "confidence in the future' aggregate (see the appendix), but not with the 'accuracy of assessments' variable. This situation was reversed in relation to $\mathrm{H} 5(\mathrm{~b})$ : the involvement of lower ranking employees failed to correlate significantly with 'confidence in the future' $(\mathrm{R}=0.08)$, but seemingly produced more accurate assessments $(\mathrm{R}=0.47)$. Notwithstanding these somewhat contradictory outcomes, hypothesis 5(a) is firmly supported. The utilisation of multidisciplinary teams (see Table 1 (q)) when future gazing was significantly associated with both the accuracy of assessments $(\mathrm{R}=0.48)$ and with confidence in the future $(\mathrm{R}=0.54)$. Associations between the Table 2 'extent of future gazing activities' variable and the satisfaction composites listed in the appendix were positive and significant. The correlation of the former with 'confidence in the future' was 0.551 ; with 'accuracy of assessments 0.49 ; and with 'performance' 0.61 .

\section{SUMMARY AND DISCUSSION}

Investment and involvement in anticipatory analysis was greatest among firms that were innately innovative, which had extensive systems and procedures for conventional planning and forecasting, and which were managed by people who believed that future business environments and client requirements would be radically different to those pertaining today. Overall the results support the view that volatile and complex environments cause managers to adopt casual and intuitive approaches to the appraisal of possible futures, presumably because the uncertainties associated with such environments make investment in future gazing not worthwhile. Firms that were heavily involved in anticipatory analysis did not appear to be more strategically flexible than others. Scenario analysis was reported to be the most popular technique for looking into the future. It seems likely that scenario construction and interpretation occurred in informal and unstructured ways, but the respondents were apparently quite familiar with the concept. Customer surveys were the least used future-gazing method. Crucially, engagement in anticipatory analysis correlated significantly with 
(i) performance satisfaction, confidence in a business's ability to cope with the future, and (iii) the accuracy of assessments. Satisfaction was enhanced by the employment of multidisciplinary teams to complete future-gazing exercises.

Advertising agencies undertook anticipatory analysis to a substantially greater degree than either PR firms or marketing research companies. In the case of PR consultancies, this result might be explained by their smaller size and hence lack of resources. There was evidence nevertheless that the PR firms in the sample were keenly interested in future gazing activities. It is relevant to note in this connection the fast-changing nature of the PR industry. ${ }^{95}$ One possible reason for advertising agencies being more likely to engage in future gazing than marketing research companies might be their greater exposure to client demands for ideas and services that are relevant to the future as well as helping clients with current operations. Research, on the other hand, typically involves the 'here and now'. Another explanation could be founded on the innate 'creativity' of the advertising industry, associated as it is with brainstorming, with devising completely novel campaigns, and with the lateral thinking that fits well with anticipatory analysis. So far as marketing research companies are concerned, conversely, perhaps it is indeed the case that concentration on mundane data gathering and interpretation, the extrapolation of trends from current and historical information, and the application of mechanical research techniques and methodologies has caused them to be less forward looking than their advertising agency counterparts. ${ }^{96,97}$

The observed connection between extensive investment in future gazing and satisfaction with financial and other performance measures clearly implies the utility of the practice. All marketing services firms should be anxious, therefore, to improve their future-gazing skills, irrespective of their specialism or sector. This could be equally true for companies in general. Unfortunately, according to Hamel and Prahalad, ${ }^{98}$ top executives typically spend less than 5 per cent of their time contemplating issues that will impact on their business's long-range futures; a situation the authors described as a 'tragic failing of the contemporary managerial mindset'. A great deal might be gained from the proactive consideration of radically different future environments and of the completely new products and services likely to succeed within them.

\section{REFERENCES}

1 Lackman, C., Saban, K. and Lanasa, J., (2000) 'The contribution of market intelligence to tactical and strategic business decisions', Marketing Intelligence and Planning, Vol. 18, No. 1, pp. 6-8.

2 Fahey, L. and Randall, M. (1998) 'Learning from the future', Wiley, New York.

3 Laczniak, G. R. and Lusch, R. F. (1997) 'The flexible executive mindset: How top management should look at tomorrow's markets', Journal of Consumer 
Marketing, Vol. 14, No. 1, pp. 60-81.

4 Simkin, L. (2000) 'Delivering effective marketing planning', Journal of Targeting, Measurement and Analysis for Marketing, Vol. 8, No. 4, p. 337.

5 Laczniak and Lush (1997) op. cit.

6 Fahey and Randall (1998) op. cit.

7 Pohl, F. (1996) 'Thinking about the future', The Futurist, Vol. 30, No. 5, pp. $8-12$.

8 Salzman, M. and Matathia, I. (1999) 'Next: The flow of the future', Harper Collins, London, p. 7.

9 Wiesbord, M. and Janoff, S. (1995) 'Future search: An action guide to finding common ground in organisations and communities', Berrett-Koehler, New York.

10 Fulmer, R. (1992) 'Nine management development challenges for the 1990s', Journal of Management Development, Vol. 11, No. 7, p. 5.

11 Ratcliffe, J. (2000) 'Scenario building: A suitable method for strategic property planning', Property Management, Vol. 18, No. 2, pp. 127-144.

12 Gutman, J. (1995) 'Creating scenarios and cases for global anticipatory learning', American Journal of Management Development, Vol. 1, No. 3, pp. 3743.

13 Fulmer, R., Gibbs, P. and Keys, J. (1998) 'New tools for sustaining competitive advantage', Organisational Dynamics, Vol. 27, No. 2, pp. 7-19.

14 Fulmer (1992) op. cit.

15 GBN Ltd. (2000) 'Scenarios', www.gbn.org/public/gbnstory/scenarios/index.htm, p. 1.

16 Gordon, W. (1999) 'Researching the future: Oxymoron or possibility?', $A d$ - map, Vol. 34, No. 4, pp. 26-29.

17 Christensen, C. M. (1997) 'The innovator's dilemma: When new technologies cause great firms to fail, Harvard University Press, Boston.

18 See also Laczniak and Lusch (1997) op. cit.

19 See also Ratcliffe (2000) op. cit.

20 Mercer, D. (1995) 'Simpler scenarios', Management Decision, Vol. 33, No. 4, pp. 32-40.

21 Gordon (1999) op. cit.

22 cf. Simkin (2000) op. cit.

23 McKiernan, P. (1997) 'Strategy past; strategy futures', Long Range Planning, Vol. 30, No. 5, pp. 790-798.

24 Mercer (1995) op. cit.

25 Fulmer et al. (1998) op. cit.

26 Ratcliffe (2000) op. cit.

27 Schwartz, P. (1991) 'The art of the long view', Doubleday, New York.

28 Fulmer et al. (1998) op. cit.

29 Jones, H. (1999) 'The art of gazing over the horizon', Financial Times, 8 February, p. 14.

30 GBN Ltd (2000) op. cit.

31 Ratcliffe (2000) op. cit.

32 Schwartz (1991) op. cit.

33 Ratcliffe (2000) op. cit.

34 Fulmer et al. (1998) op. cit.

35 Ibid

36 Gordon (1999) op. cit.

37 Ibid., p. 28

38 Balmer, J. M. (1998) 'Corporate identity and the advent of corporate marketing', Journal of Marketing Management, Vol. 14, No. 8, pp. 963-996.

39 cf. Gordon (1999) op. cit.

40 Jones, H. (1997) 'An epidemic of futures', Financial Times, 22 December, p. 9. 
41 Ibid., p. 9.

42 Gordon (1999) op. cit., p. 27

43 Christensen (1997) op. cit.

44 Cooper, L. G. (2000) 'Strategic marketing planning for radically new products', Journal of Marketing, Vol. 64, No. 1, pp. 1-16.

45 Whipp, R., Rosenfeld, R. and Pettigrew, A. M. (1987) 'Understanding strategic change processes: Some preliminary British findings', in Pettigrew, A. M. (ed.) 'The management of strategic change', Basil Blackwell, Oxford, pp. 14-55.

46 Wilson, D. F. (1999) 'Competitive marketing strategy in a volatile environment: Theory, practice and research priorities', Journal of Strategic Marketing, Vol. 7, No. 1, pp. 19-40.

47 Ibid., p. 20.

48 Cooper (2000) op. cit., p. 1.

49 Bahrami, H. and Evans, S. (1989) 'Strategy making in high-technology firms: The empiricist mode', California Management Review, Vol. 31, No. 2, pp. 107-128.

50 Wilson (1999) op. cit., p. 20.

51 See Wilson (1999) op. cit., pp. 21-22 for information on the literature support each point of view.

52 Elenkov, D. (1997) 'Strategic uncertainty and environmental scanning: The case for institutional influences on scanning behaviour', Strategic Management Journal, Vol. 18, No. 4, pp. 287-313.

53 See Muses, C. (2000) 'Simplifying complexity: The greatest present challenge to management and government', Kybernetes, Vol. 29, No. 5/6, pp. $612-637$, for a review and discussion of various types of environmental complexity.

54 Whipp et al. (1987) op. cit.

55 Boynton, A. C. and Victor, B. (1991) 'Beyond flexibility: Building and managing the dynamically stable organisation', California Management Review, Vol. 34, No. 1, pp. 53-66.

56 See Wilson (1999) op. cit., p. 21 for details of relevant studies.

57 See Fletcher, K., Wright, G. and Desai, C. (1996) 'The role of organisational factors in the adoption and sophistication of database marketing in the UK financial services industry', Journal of Direct Marketing, Vol. 10, No. 1, pp. 10-21, for details of relevant studies.

58 Wilson (1999) op. cit., p. 21.

59 Pohl (1996) op. cit.

60 Ratcliffe (1996) op. cit.

61 Metcalfe, M. (1994) 'Forecasting profit', Kluwer, Boston.

62 Mercer (1995) op. cit.

63 See Laczniak and Lusch (1997) op. cit. 64 cf. Deshpande, R. and Webster, F. (1989) 'Organisational culture and marketing: Defining the research agenda', Journal of Marketing, Vol. 53, No. 1, pp. 3-16.

65 Bennett, R. and Gabriel, H. (1999) 'Organisational factors and knowledge management within large marketing departments', Journal of Knowledge Management, Vol. 3, No. 3, pp. 212-225.

66 Fulmer (1992) op. cit.

67 Gutman (1995) op. cit.

68 Pohl (1996) op. cit.

69 Fahey and Randall (1998) op. cit.

70 Gordon (1999) op. cit.

71 Schwartz (1991) op. cit. 
72 Metcalfe (1994) op. cit.

73 Mercer (1995) op. cit.

74 Gordon (1999) op. cit.

75 Bahrami and Evans (1989) op. cit.

76 Boynton and Victor (1991) op. cit.

77 Christensen (1997) op. cit.

78 Ratcliffe (2000) op. cit.

79 Weisbrod and Janoff (1995) op. cit.

80 Lacznick and Lusch (1997) op. cit.

81 Wilson (1999) op. cit.

82 Cooper (2000) op. cit.

83 Lackman et al. (2000) op. cit.

84 Whipp et al. (1987) op. cit.

85 Fletcher et al. (1996) op. cit.

86 Fulmer et al. (1998) op. cit.

87 Salzman and Matathia (1999) op. cit.

88 Fletcher et al. (1996) op. cit.

89 Fulmer et al. (1998) op. cit.

90 Bahrami and Evans (1989) op. cit.

91 Elenkov (1997 op. cit.

92 Wilson (1999) op. cit.

93 Cooper (2000) op. cit.

94 Muses (2000) op. cit.

95 Balmer (1998) op. cit.

96 Christensen (1997) op. cit.

97 Gordon (1999) op. cit.

98 Hamel, G. and Prahalad, C. K. (1994)

'Competing for the future', Harvard

Business School Press, Boston, p. 17.

\section{APPENDIX: CONSTRUCTS AND QUESTIONNAIRE ITEMS}

\section{A. Organisational flexibility $($ alpha $=0.79)$}

(i) This firm prefers not to make any major changes without first gaining experience in the area or issue concerned.

(ii) This organisation can quickly reallocate its resources and undertake new activities in order to exploit emerging opportunities.

(iii) Our strategies respond very quickly to competitors' actions.

(iv) This organisation responds very quickly to challenging situations.

(v) This firm is very flexible.

B. Innovativeness (alpha $=\mathbf{0 . 8 8})$

(i) This firm is very innovative.

(ii) Within this firm, unconventional approaches are encouraged and rewarded.

(iii) The culture within this firm is very change friendly.

(iv) This firm is prepared to take big risks in order to stay ahead of the field.

(v) This firm strives to be among the first to introduce the very latest methods.

\section{The external environment \\ $(\mathrm{R}=\mathbf{0 . 6 1})$}

(a) Competitive intensity

(i) Competition from other firms is intense.

(ii) New competing firms regularly enter our markets.

(iii) If we are successful in our activities, competing firms immediately copy the things we have done.

(b) Volatility (alpha $=0.91$ )

The business environment in which we operate is:

(i) highly volatile

(ii) uncertain 
(iii) turbulent

(iv) constantly changing.

Complexity (alpha $=0.89$ )

The business environment in which we operate:

(i) is very complicated

(ii) is very difficult to understand

(iii) contains many unknowns

(iv) is difficult to measure and predict

(v) has many elements which cannot be identified.

(d) General

(i) Our clients are constantly demanding new types and forms of services.

\section{Satisfaction measures}

$(\mathbf{R}=\mathbf{0 . 7 7})$

(a) Confidence in the future

(i) This firm is well equipped to deal with future eventualities. (ii) We are confident that we will be able to cope with future business environments and client requirements.

(iii) We believe that the future holds exciting challenges that are not to be feared.

(b) Accuracy of assessments ( $R=0.68$ )

(i) Our assessments of what the future holds for us usually come true.

(i) Overall, we are satisfied with the effectiveness of our future-gazing activities.

(c) Performance $(R=0.7)$

(i) Relative to our competitors our financial performance has been highly satisfactory.

(ii) Overall we are highly satisfied with the firm's performance.

(iii) Clients are generally delighted with the range of services we offer. 
